\title{
Psychophysical correlates of phantom limb experience
}

Joel Katz

\begin{abstract}
Phantom limb phenomena were correlated with psychophysiological measures of peripheral sympathetic nervous system activity measured at the amputation stump and contralateral limb. Amputees were assigned to one of three groups depending on whether they reported phantom limb pain, non-painful phantom limb sensations, or no phantom limb at all. Skin conductance and skin temperature were recorded continuously during two 30 minute sessions while subjects continuously monitored and rated the intensity of any phantom limb sensation or pain they experienced. The results from both sessions showed that mean skin temperature was significantly lower at the stump than the contralateral limb in the groups with phantom limb pain and nonpainful phantom limb sensations, but not among subjects with no phantom limb at all. In addition, stump skin conductance responses correlated significantly with the intensity of non-painful phantom limb paresthesiae but not other qualities of sensation or pain. Between-limb measures of pressure sensitivity were not significantly different in any group. The results suggest that the presence of a phantom limb, whether painful or painless, is related to the sympathetic-efferent outflow of cutaneous vasoconstrictor fibres in the stump and stump neuromas. The hypothesis of a sympathetic-efferent somatic-afferent mechanism involving both sudomotor and vasoconstrictor fibres is proposed to explain the relationship between stump skin conductance responses and non-painful phantom limb paresthesiae. It is suggested that increases in the intensity of phantom limb paresthesiae follow bursts of sympathetic activity due to neurotransmitter release onto apposing sprouts of large diameter primary afferents located in stump neuromas, and decreases correspond to periods of relative sympathetic inactivity. The results of the study agree with recent suggestions that phantom limb pain is not a unitary syndrome, but a symptom class with each class subserved by different aetiological mechanisms.
\end{abstract}

(F Neurol Neurosurg Psychiatry 1992;55:811-821)

More than $90 \%$ of amputees report a persisting, sensory awareness of the cut off part. ${ }^{1}$ This phenomenon has been termed the phantom limb and is usually described as having a tingling or numb quality. For many amputees, however, a distressing problem is pain in the phantom limb. Recent surveys based on several thousand amputees reveal that $70 \%$ continue to experience phantom limb pain years after amputation. ${ }^{2}$ In the long term only $7 \%$ of patients are helped by the more than 50 types of therapy used to treat phantom limb pain. ${ }^{3}$ This intractability reflects our ignorance about the mechanisms that contribute to phantom limb pain.

Recently, Sherman et $a l^{4}$ have argued that phantom limb pain is not a unitary syndrome, but a symptom class, with each class subserved by different aetiological mechanisms. For example, one class of phantom limb pain which is characterised by a cramping quality is associated with EMG spike activity in muscles of the stump whereas burning phantom limb pain shows no such association. ${ }^{4}$ Katz and Melzack $^{5}$ have identified a class of phantom limb pain which resembles in quality and location a pain experienced in the limb before amputation. Although the precise physiological mechanisms that underlie these somatosensory pain memories are unknown, the presence of pre-amputation pain clearly is a necessary condition for these phantom pains to develop.

Another class of phantom limb pain may come about through involvement of the sympathetic nervous system. Sympathetically maintained pains have been attributed to sympathetically-triggered ephaptic transmission, ${ }^{6}$ sympathetic activation of sensitised nociceptors $^{7}$ or low threshold mechanoreceptors which terminate on sensitised spinal cord cells $^{8}$ and injury-induced alteration in the pattern of postganglionic cutaneous vasoconstrictor neurons which lose their normal thermoregulatory function leading to trophic changes and ischaemia. ${ }^{6}$

Evidence of sympathetic involvement among amputees comes from studies which pharmacologically block ${ }^{9}$ or surgically interrupt ${ }^{10}$ the sympathetic supply to the involved limb producing at least temporary alleviation of pain. Transient relief from phantom limb pain has been reported with propranalol, a betaadrenergic blocking agent. ${ }^{11}$ Electrical or mechanical stimulation of the lumbar sympathetic chain produces intense pain referred to the phantom limb, ${ }^{1213}$ whereas sensations are referred to the abdomen or flank in patients experiencing pain without amputation. ${ }^{12}$

Surprisingly few studies have compared cor- 
relates of peripheral sympathetic nervous system activity at the stump and contralateral limb of human amputees. Sliosberg ${ }^{14}$ examined 141 amputees and found that the stump was cooler than the intact limb in 94 patients but he did not relate the temperature differences to the presence or absence of phantom limb pain. Kristen et $a l^{15}$ reported that a "patchy asymmetrical temperature" distribution of stump thermograms was significantly more frequent among stump pain sufferers than in patients who were free from stump pain, but thermograms were no different for patients with or without phantom limb pain. Nyström and Hagbarth ${ }^{16}$ made microneurographic recordings of activity from muscle nerve fascicles of the peroneal nerve in a patient with a below-knee amputation who suffered from intense cramping pain referred to the phantom foot. Although bursts of activity in sympathetic fibres were accentuated by the Valsalva manoeuvre, the phantom pain remained unchanged suggesting that, in this patient, the cramping pain was independent of peripheral sympathetic nervous system activity.

In contrast, Sherman et $a l^{17} 18$ recently observed a negative correlation between temperature at the stump and the presence of burning phantom limb and stump pain indicating that reduced blood flow to the stump is associated with increased levels of pain. Repeated measurements of the same patients on different occasions revealed that lower temperatures at the stump relative to the contralateral limb were associated with greater intensities of phantom limb and stump pain. In the majority of cases, however, the relationship between phantom pain and limb temperature was confounded by co-existing stump pain, and so it is not possible to unambiguously attribute the presence of phantom limb pain to altered blood flow at the stump. In addition, decreased blood flow to the stump may be a feature of all stumps regardless of the patient's status with respect to phantom limb pain.

Further evidence of a link between sympathetic nervous system activity at the stump and phantom limb sensations was furnished by Katz et $a^{19}$ who demonstrated an association between stump skin conductance and the intensity of non-painful phantom limb paresthesiae. Stump skin conductance correlated significantly with the intensity of phantom limb paresthesiae during two 60-minute sessions in a patient with a non-painful phantom limb. Their results suggest that phantom limb paresthesiae may in part be explained by a cycle of sympathetic-efferent primary afferent activity. Post-ganglionic sympathetic sudomotor and vasomotor fibres located in the stump may produce a phasic pattern of neurotransmitter release which alters the firing rate of adjacent primary afferents projecting onto spinal cord cells subserving the portion of the limb which is missing. Katz et $a l^{19}$ proposed that this fluctuating pattern of activity is transmitted rostrally where it is perceived as increases and decreases in the intensity of phantom limb paresthesiae.
Taken together, certain qualities of phantom limb sensation and pain may have peripheral triggers involving sympathetic-somatic links, but further study is required to assess the nature of this relationship in amputees with painful or non-painful phantoms as well as in those without phantom limbs. This study was designed to compare skin temperature, skin conductance and pressure sensitivity thresholds of the stump and contralateral limb in three groups of amputees: 1) Group PLP with phantom limb pain; 2) Group PLS with nonpainful phantom limb sensations, and 3) Group No PL with no phantom limb. Based on previous work by Sherman et al ${ }^{17}$ it was proposed that subjects with phantom limb pain would show significantly lower mean skin temperature at the stump relative to the contralateral limb. In addition, based on the results of Katz et $a l^{19}$ it was proposed that measurements of stump skin conductance obtained over time would correlate significantly with the intensity of non-painful paresthesiae referred to the phantom limb.

\section{Method}

Sample The sample and recruitment procedures for this study have been described in detail elsewhere. ${ }^{20}$ The subjects were $28 \mathrm{ampu}$ tees (18 males and 10 females) who had undergone amputation of the upper extremity (above-elbow in 2; below in 1) or lower extremity (above-knee in 16; below in 9). The reason for amputation was peripheral vascular disease (including diabetes mellitus) in 12 subjects, accident in 9, arterial thrombosis in 3 , tumour in 2, and one each for radiation damage and polio. The mean age and time since amputation was 52.8 years (range: 23 to 73 years) and five years (range: 36 days to 46 years), respectively. Patients with dementia or acute psychopathology were excluded.

The subjects were assigned to one of three groups on the initial session based on the presence or absence of painful or non-painful phantom limb sensations at the time of testing. Group PLS consisted of 9 amputees who reported feeling only non-painful phantom limb sensations, group PLP consisted of 11 subjects who reported phantom limb pain, and group No PL consisted of 8 amputees who reported that they did not feel the presence of a phantom limb at all. Two subjects in group No PL and one in group PLP reported stump pain of a burning quality on both sessions. One subject in group PLS reported non-painful tingling sensations in the stump on both sessions. All other subjects were free of stump pain or other stump sensations.

Experimental apparatus Skin conductance measurements taken at homologous points on the stump and contralateral limb were obtained using a portable Thought Technology biofeedback module with digital display (SC200T) and $\mathrm{Ag} / \mathrm{AgCl}$ Beckman electrodes. The electrode paste consisted of a mixture of physiological saline and a neutral ointment cream with the recommended concentration of approximately 0.05 molar $\mathrm{NaCl}^{21}$ Surface 
skin temperature measurements at the stump and contralateral limb were obtained using a Yellow Springs Instruments (YSI) digital thermometer, Model 49TA, and 2 YSI Model 409A temperature probes. The Model 49TA has an ambient temperature range of $-10^{\circ}$ to $+50^{\circ} \mathrm{C}$ with a resolution of $0.01^{\circ} \mathrm{C}$ and is accurate to $\pm 0.05^{\circ} \mathrm{C}$ within a range of $30^{\circ}-40^{\circ} \mathrm{C}$. Skin conductance and skin temperature leads from each limb were connected to a two-channel electromechanical relay that switched channels every 10 seconds. The output from the relay fed into the skin conductance and skin temperature modules which alternated between displaying information from the stump and contralateral limb every 10 seconds.

The subject rated changes in perceived phantom limb intensity of painful or nonpainful sensations by turning a dial which allowed 180 degrees of rotation. The 90 degree setting was labelled "USUAL", 0 degrees, "LESS", and 180 degrees, "MORE". The dial was connected to a 1.35 volt mercury battery via a $10000 \mathrm{ohm}$ potentiometer and the output fed into a digital volt meter which registered 0 through 0.675 to 1.35 volts corresponding to the 0,90 , and 180 degree settings of the dial, respectively. Data acquisition was accomplished by videotaping the digital output of the skin conductance, skin temperature, and phantom limb intensity displays during each 30 minute session. A digital stopwatch which was started at the beginning of each session, was also filmed to provide a reference point when transcribing the raw data values for subsequent analysis.

Skin sensitivity to pressure was assessed using the Semmes-Weinstein pressure aesthesiometer (Shaw Laboratories, New York) which consists of a set of 20 individual nylon filaments of equal length ( $38 \mathrm{~mm}$ ) ranging from 0.06 to $1.14 \mathrm{~mm}$ in diameter. Each filament has been assigned a value that represents the logarithm of the force (in $\mathrm{mg}$ ) required to bend it maximally when pressed against the skin.

The McGill Pain Questionnaire ${ }^{22}$ was used to obtain quantitative and qualitative measures of the experience of pain. The questionnaire yields two global scores, the total pain rating index and the present pain intensity. The total pain rating index is the sum of the rank values of the words chosen from 20 sets of qualitative words, each set containing two to six adjectives that describe sensory, affective, evaluative, and miscellaneous properties of pain. The lists of pain descriptors are read to the patients who are asked to choose the word in each category that best describes their pain at the moment. The present pain intensity is rated on a scale of zero to five as follows: $0=$ none, $1=$ mild, $2=$ discomforting, $3=$ distressing, $4=$ horrible, and 5 = excruciating.

Procedure The investigator scheduled 2 sessions for the same time on consecutive days or with as few days intervening between sessions as could be arranged. Subjects were requested to refrain from smoking and drinking coffee and alcohol on the days they were to be seen. Those with phantom limb pain were asked not to take any pain medication on the days they had been scheduled in order to maximise potential between-group differences in skin conductance and temperature, and to obtain an accurate, medication-free description of the pain.

Informed written consent was obtained after the experimental procedures were explained. The subjects removed their prostheses and uncovered the homologous region of the contralateral limb 30 minutes before data collection to allow the limbs to adjust to the conditions in the room. The experimenter cleaned the stump and contralateral limb with alcohol and placed the skin conductance electrodes and temperature probes on the distal portion of the stump approximately $5 \mathrm{~cm}$ from its end, and at mirror-image regions on the contralateral limb.

Mirror-image points on the two limbs were marked with a felt-tipped pen to identify stimulation sites for pressure sensitivity. Pressure sensitivity thresholds were obtained first from the stump and then the other limb. Strands of hair surrounding the selected points were carefully cut before sensory testing to ensure that the filaments came in contact with the skin only. The subjects closed their eyes and stated when they felt they had been touched. On each trial, a filament was applied to the designated point on skin for approximately one second. Trials were separated by an interval ranging from five to fifteen seconds to reduce the likelihood of anticipatory responses. Filaments were applied in ascending serial order until the subject had correctly responded on five consecutive trials. Pressure sensitivity threshold was defined by the value associated with the filament that had been used on the first of these five trials (that is, the filament with the smallest diameter).

The subjects then completed the McGill Pain Questionnaire and several mood and anxiety rating scales. Video recording of the stopwatch, skin conductance, skin temperature, and phantom limb intensity displays was initiated after the subjects had practised using the dial and had begun monitoring their phantom limb. The subjects were told that whenever they registered a change in phantom limb intensity by turning the dial, they were also to provide a brief description of the quality of the phantom limb sensation or pain.

Psychophysiological data reduction The videotape from each session was reviewed and one value of skin conductance, skin temperature and phantom limb intensity was obtained every 10 seconds for both 30 minute sessions. Mean values of phantom limb intensity were transformed by subtracting a constant of 0.675 from each. This served to relocate the scores so that the 90 degree position of the dial labelled "USUAL" took on a value of 0.0 , and deviations from it, in the clockwise and counter-clockwise directions (corresponding to increases and decreases in phantom limb intensity), had maximum values of $\pm 0 \cdot 675$, respectively.

The audio portion of the videotape from each session was transcribed verbatim for each 
Pressure Sensitivity Threshold

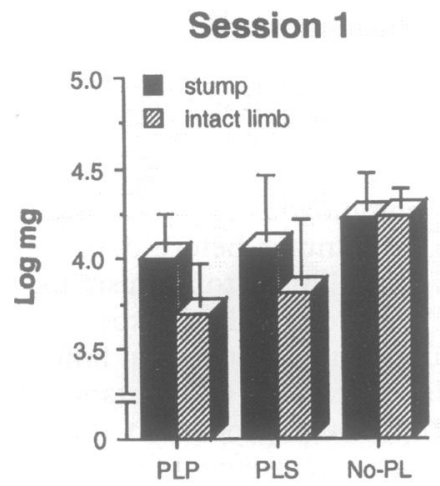

\section{Skin Conductance}
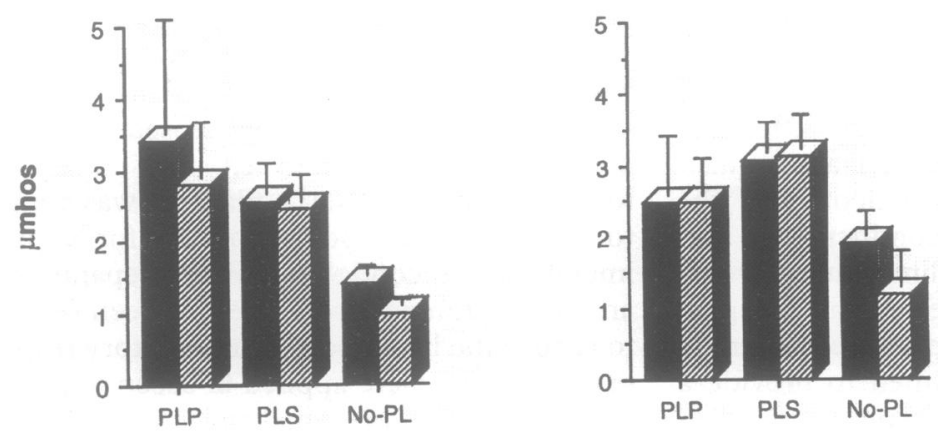

Skin Temperature
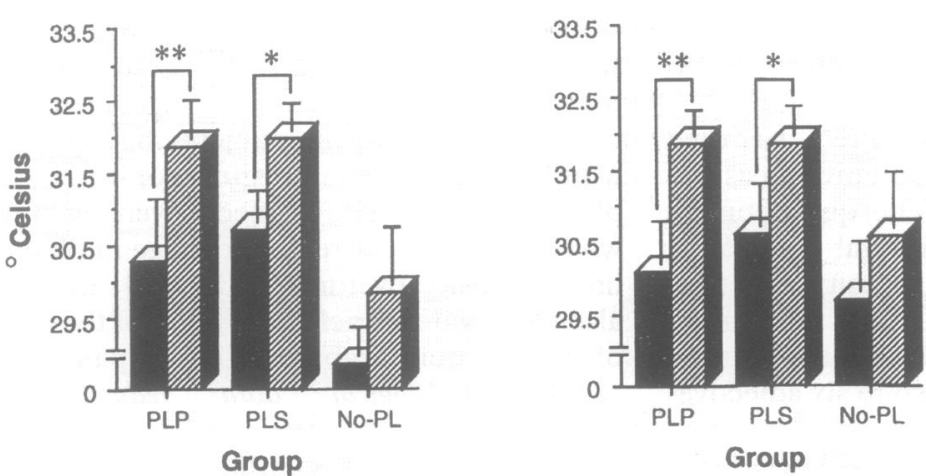

Figure 1 Mean pressure sensitivity thresholds, skin conductance and skin temperature of the stump and contralateral limb displayed for the 3 groups of amputees on both sessions. PLP refers to phantom limb pain; PLS, non-painful phantom limb sensations; No PL, no phantom limb at all. Mean stump skin temperature was significantly lower than the contralateral limb on both sessions for Groups PLP $\left(\star_{p}^{*}<0.005\right)$ and PLS $\left({ }^{*} p<0.05\right)$ but not Group No PL.

subject. Every verbal description of phantom limb pain (or sensation) was recorded in terms of its quality (for example, tingling, shooting), and time-matched to the corresponding change in phantom limb intensity which the subject had registered using the dial.

\section{Results}

Group differences in psychophysiological measurements Figure 1 shows the mean pressure sensitivity thresholds, skin conductance level, and skin temperature, obtained at each limb for the three groups of amputees on the two sessions. Each variable was entered into a 3-way ANOVA using group (PLP, PLS, No $P L)$ as the independent-samples factor, and Session $(1,2)$ and Limb (stump, contralateral) as the repeated-measurements factors. The analysis of skin temperature revealed a significant main effect for the limb factor indicating that overall stump skin temperature was significantly lower than that of the contralateral limb. All other main effects and interactions were not significant $(p>0.05)$.

The theory that stump skin temperature would be significantly lower than the contralateral limb in group PLP was tested by planned comparisons of the two limbs on sessions 1 and 2 . As displayed in fig 1 , the stump was significantly cooler than the contralateral limb for subjects in group PLP and group PLS on both sessions (group PLP: $F$ (1, $25)=9.79$, and 10.4 for sessions 1 and 2 , respectively, both $\mathrm{p}<0.005$; group PLS: $F(1$, $25)=5.05$ and 4.32 , both $p<0.05$ ). For group No PL, however, the mean temperature difference between the limbs failed to reach significance on either session $(F$ (1, $25)=2.17$ and 1.99 for sessions 1 and 2 respectively, both $p>0.05)$. The results indicate that the presence of a phantom limb, whether painful or painless, is associated with significantly lower skin temperature on the stump than the contralateral limb.

Group differences in the intensity and quality of phantom limb sensations Table 1 shows the mean McGill Pain Questionnaire scores for groups PLP and PLS corresponding to the

Table 1 Mean McGill Pain Questionnaire (MPQ) present pain intensity scores and pain rating indexes (PRI) for the sensory, affective, evaluative, miscellaneous, and total classes presented for Groups PLP and PLS on sessions 1 and 2. Standard deviations are contained in brackets. P-values correspond to the ANOVA F-test comparing group means. Note that unlike Group PLP, the PRIs from Group PLS do not represent pain intensity, but instead, intensity of non-painful phantom limb sensations.

For this reason, all present pain intensity ratings from Group PLS have a value of zero, corresponding to the $M P Q$ descriptor "no pain"

\begin{tabular}{|c|c|c|c|}
\hline & \multicolumn{3}{|l|}{ Session 1} \\
\hline & $\begin{array}{l}\text { Group PLP } \\
(n=11)\end{array}$ & $\begin{array}{l}\text { Group PLS } \\
(n=9)\end{array}$ & p-value \\
\hline \multirow[t]{3}{*}{$\begin{array}{l}\text { MPQ Class } \\
\text { PRI-Sensory } \\
\text { PRI-Affective } \\
\text { PRI-Evaluative } \\
\text { PRI-Miscellaneous } \\
\text { PRI-Total } \\
\text { Present pain intensity }\end{array}$} & $\begin{aligned} 9 \cdot 0(7 \cdot 3) \\
2 \cdot 9(2 \cdot 8) \\
1 \cdot 5(1 \cdot 1) \\
3 \cdot 7(2 \cdot 7) \\
17 \cdot 1(11 \cdot 1) \\
2 \cdot 2(1 \cdot 1)\end{aligned}$ & $\begin{array}{l}3.2(4 \cdot 7) \\
0.0 \\
0.6(0.5) \\
1.3(1 \cdot 6) \\
5 \cdot 1(6 \cdot 0) \\
0.0\end{array}$ & $\begin{array}{l}0.004 \\
0.001 \\
0.001 \\
0.001 \\
0.0002 \\
-\end{array}$ \\
\hline & \multicolumn{3}{|l|}{ Session 2} \\
\hline & $\begin{array}{l}\text { Group PLP } \\
(n=11)\end{array}$ & $\begin{array}{l}\text { Group PLS } \\
(n=9)\end{array}$ & p-value \\
\hline $\begin{array}{l}\text { MPQ Class } \\
\text { PRI-Sensory } \\
\text { PRI-Affective } \\
\text { PRI-Evaluative } \\
\text { PRI-Miscellaneous } \\
\text { PRI-Total } \\
\text { Present pain intensity }\end{array}$ & $\begin{array}{c}9 \cdot 1(5 \cdot 9) \\
1.5(2 \cdot 4) \\
1.5(1 \cdot 0) \\
3.6(3 \cdot 3) \\
15.7(11 \cdot 6) \\
1.9(0 \cdot 7)\end{array}$ & $\begin{array}{l}2.8(2 \cdot 7) \\
0.1(0.3) \\
0.4(0.7) \\
1.7(1 \cdot 5) \\
5.0(4 \cdot 0) \\
0.0\end{array}$ & $\begin{array}{l}0.0001 \\
0.06 \\
0.001 \\
0.006 \\
0.0004 \\
-\end{array}$ \\
\hline
\end{tabular}




\section{Case E02}

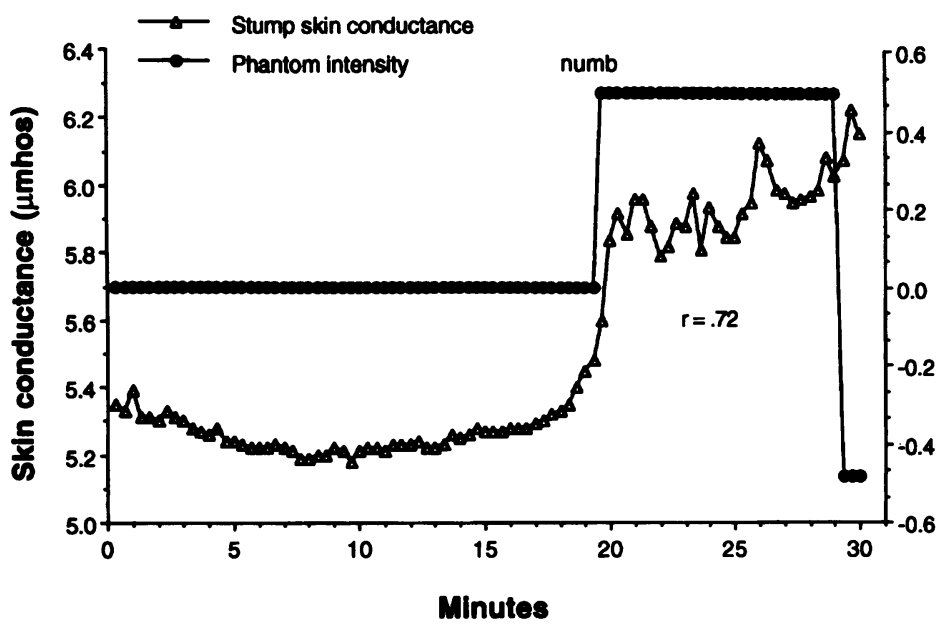

Case E08

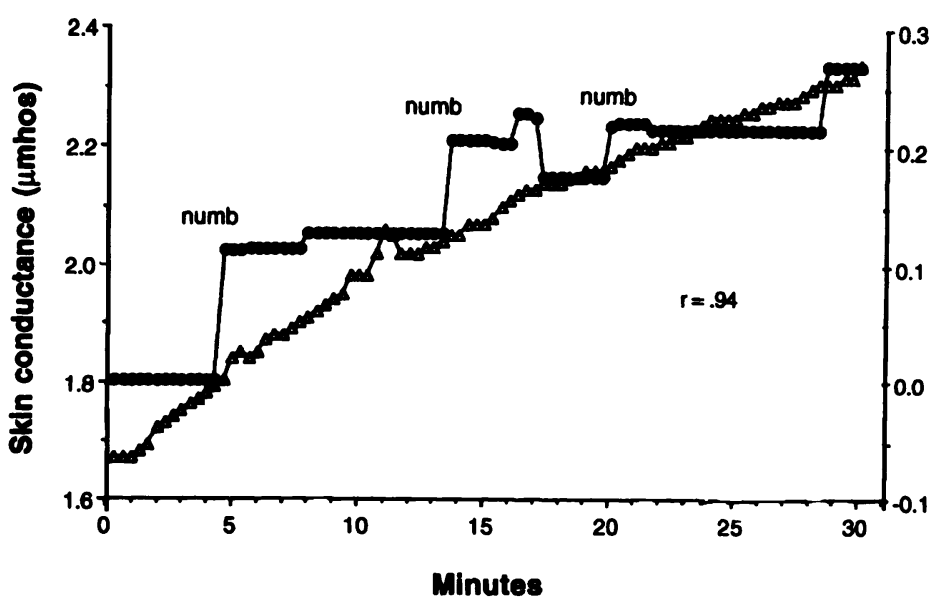

Figure 2 Plots of the relationship between stump skin conductance and the intensity of phantom limb paresthesiae for two subjects in Group PLS. Skin conductance was measured at the stump over a 30 minute period while the subjects monitored the intensity of the phantom limb by turning a dial. Phantom limb intensity ratings have been transformed so that a value of 0.0 represents the intensity at the start of the session and deviations from it correspond to increases and decreases in phantom limb intensity. Changes in the intensity of paresthesiae (described as increases and decreases in "numb" sensations referred to the phantom limb) occur in concert with changes in stump skin conductance. Also shown is the correlation coefficient describing the strength of the relationship between the two variables and the subjects' descriptions of the quality of the phantom sensation. Abbreviations as in fig 1.

intensity of the painful or non-painful phantom limb on sessions 1 and 2 . As can be seen, mean pain rating indexes for group PLP are significantly higher than those for group PLS on both sessions, consistent with the fact that the former group comprises subjects with phantom limb pain, and the latter, non-painful phantom limb sensations.

In addition to these quantitative differences, the quality of the phantom limbs in the two groups also differed. Table 2 shows the McGill Pain Questionnaire adjectives chosen by 33\% or more of subjects in groups PLS and PLP to describe the various qualities of phantom limb sensation or pain. The descriptors selected by group PLS (for example, "pricking", "tingling", "numb") indicate that the painless phantom limb is defined primarily by paresth- esiae whereas the qualities of sensation that describe the painful phantom are more varied. Nevertheless, there is a consistency in the choice of descriptors between groups: every descriptor chosen by $33 \%$ or more of subjects in group PLS was also chosen by $33 \%$ or more subjects in group PLP, although other descriptors were also endorsed by the latter group with greater frequency.

Further evidence that the painful phantom limb embodies more than the basic paresthetic quality characteristic of the painless phantom comes from an analysis of the different qualities of sensation subjects reported when monitoring their phantom limb during the two 30 minute observation periods. Chi square analyses using Yates' correction for continuity confirm that the qualities of sensation reported by subjects with phantom limb pain were more varied than those with non-painful phantom limbs. Taken together, these data reveal that the phantom limb experiences of the two groups have in common a paresthetic quality, although painful phantoms consist of more than this shared component and included sensations of pressure, constriction, throbbing, pulsating, pumping sensations and somatosensory pain memories.

Between-subject correlations of pain ratings and psychophysiology. Pearson correlation coefficients were computed between the psychophysiological measurements taken at the two limbs and the McGill Pain Questionnaire ratings for all 28 subjects on the two sessions. Also computed were the correlation coefficients describing the relationship between the limb difference scores and McGill Pain Questionnaire ratings. Limb difference scores shown in table 3 were obtained by subtracting measurements taken at the contralateral limb from those at the stump. Negative difference scores indicate that relative to the contralateral limb the stump is lower in temperature, lower in skin conductance, and more sensitive to applied pressure.

Correlation coefficients ranged between $r$ (26) $=0.37$ and $r(26)=0.33$, indicating that at most $14 \%$ of the variance in pain ratings could be explained by the psychophysiological variables. Using Bonferonni's correction for multiple tests of significance, even the highest coefficient failed to reach significance (all p $>0.05)$. Mean skin temperature, skin con-

Table 2 McGill Pain Questionnaire (MPQ) descriptors chosen by $33 \%$ or more of subjects in Groups PLP and

$P L S$ to describe the sensations experienced in the phantom limb. Note that the adjectives chosen by Group PLP describe phantom limb pain, and those chosen by Group $P L S$ describe non-painful phantom limb sensations

\begin{tabular}{lll}
\hline MPQ Class & Group PLP $(n=11)$ & Group PLS $(n=9)$ \\
\hline Sensory & $\begin{array}{l}\text { Pricking } \\
\text { Sharp } \\
\text { Hot } \\
\text { Tingling } \\
\text { Tiring } \\
\text { Sickening } \\
\text { Affective }\end{array}$ & Pricking \\
& $\begin{array}{l}\text { Punishing } \\
\text { Wretched } \\
\text { Annoying } \\
\text { Evaluative } \\
\text { Miscellaneous } \\
\text { Numb }\end{array}$ & Tingling \\
& Nagging & Annoying \\
& Numb \\
\hline
\end{tabular}




\section{Case E23}

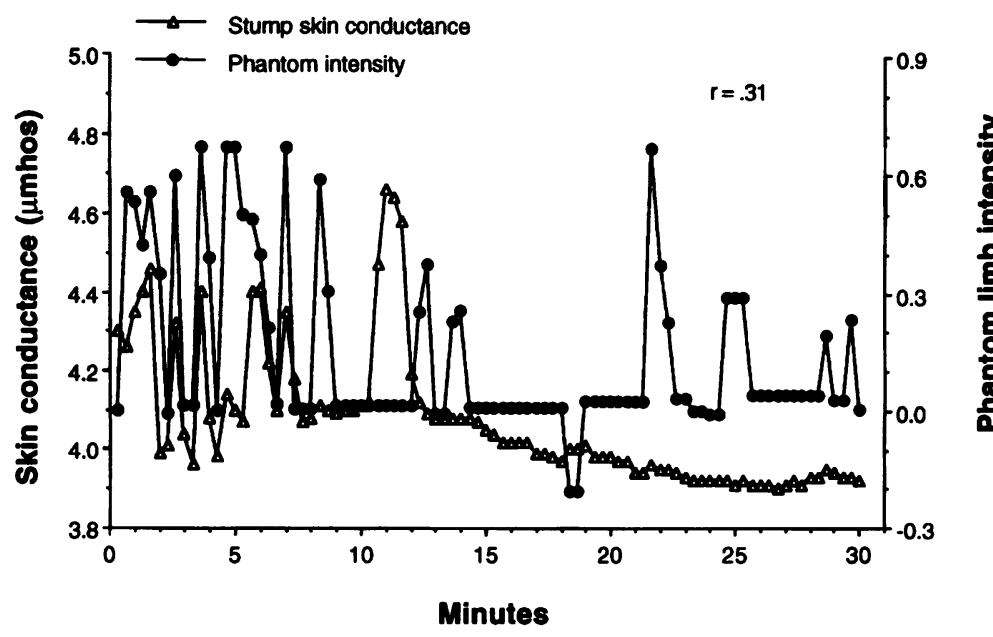

Case E23

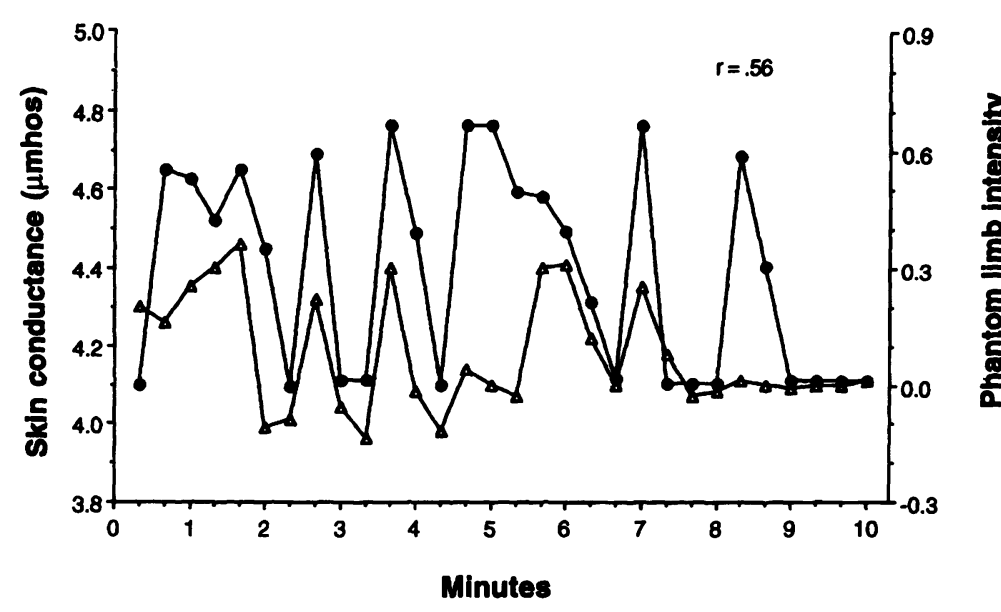

Figure 3 The relationship between stump skin conductance and phantom limb intensity for a subject in Group PLS shown for one entire 30 minute session (top panel). For ease of viewing, the bottom panel shows only the first 10 minutes of the same session when the two measures showed a prominent tendency to covary. All changes in phantom limb intensity were described by the subject as increases and decreases in "numbness" experienced in the phantom foot. Abbreviations as in fig 1.

ductance, or pressure sensitivity threshold of either limb does not appear to be related to the intensity of phantom limb pain or sensations. Nor is the magnitude of the mean difference between the limbs associated with the intensity of the McGill Questionnaire pain ratings. There is no simple linear relationship between the psychophysiological measurements and phantom limb pain intensity. Overall, subjects with large limb difference scores do not report high pain scores and those with little or no difference between limbs do not report little or no pain.

Relationship between phantom limb intensity and stump skin conductance The relationship between changes in stump skin conductance and the intensity of phantom pain/sensation across both 30 minute sessions was assessed for each subject by Pearson correlation coefficients and by plotting the two variables together as a function of time. Figures 2 and 3 show plots of the relationship between stump skin conductance and the intensity of non- painful phantom limb paresthesiae for 3 subjects in group PLS. Figure 4 shows the relationship between stump skin conductance and the intensity of phantom limb pain comprised of various qualities of sensation for 2 subjects in group PLP. There is a pronounced tendency for increases and decreases in the intensity of phantom limb paresthesiae to be accompanied by similar changes in stump skin conductance for subjects in group PLS (figs 2 and 3 ). In contrast, changes in the intensity of phantom limb pain and stump skin conductance occur independently with little or no tendency for the two measures to covary (fig 4).

Table 4 shows the number of subjects in the two groups with significant correlations (using Bonferonni's type I error rate correction for multiple tests of significance) between phantom limb intensity and stump skin conductance and temperature. The mean correlation coefficient between these measures for the two groups is also shown. The most salient feature of these data is that the majority of subjects in group PLS show significant positive correlations whereas this is not the case for group PLP (table 4). A chi-square analysis comparing the frequency of significant and non-significant correlations between the groups was significant $\left(\chi^{2}(1)=3.65, \mathrm{p}<0.06\right)$ indicating that there is a significant positive relationship between stump skin conductance and phantom limb intensity for proportionally more subjects in group PLS than group PLP (for example, figs 2-4).

A one way between-groups ANOVA was carried out on the mean correlation coefficient between phantom limb intensity and stump skin conductance (sessions 1 and 2 combined). Group PLS demonstrated a significantly stronger linear relationship than group PLP ( $F(1$, 29) $=7.15, p<0.01$ ) indicating that, on average, the proportion of the total shared variance is greater in group PLS than group PLP. Finally, the relationship between phantom limb intensity and stump skin conductance was significantly greater than zero for

Table 3 Mean stump-intact limb difference scores for pressure sensitivity thresholds (PST), skin conductance
(SC), and skin temperature (ST) presented for the three (SC), and skin temperature (ST) presented for the
groups of amputees on sessions 1 and 2. Standard deviations are contained in brackets. Stump-intact limb difference scores were obtained by subtracting

difference scores were obtained by subtracting
measurements taken at the intact limb from those at the stump. Negative difference scores indicate that relative to the intact limb the stump is lower in skin temperature, lower in skin conductance, and more sensitive to applied pressure

\begin{tabular}{|c|c|c|c|}
\hline & \multicolumn{3}{|l|}{ Session 1} \\
\hline & $\begin{array}{l}\text { Group PLP } \\
(n=11)\end{array}$ & $\begin{array}{l}\text { Group PLS } \\
(n=9)\end{array}$ & $\begin{array}{l}\text { Group No PL } \\
(n=8)\end{array}$ \\
\hline \multirow[t]{3}{*}{$\begin{array}{l}\text { PST (log mg) } \\
\text { SC ( } \mu \mathrm{mhos}) \\
\text { ST ('Celsius) }\end{array}$} & $\begin{array}{r}0.31(1.3) \\
0.61(3.0) \\
-1.59(1.8)\end{array}$ & $\begin{array}{r}0.25(1.2) \\
0.11(0.7) \\
-1.26(1.3)\end{array}$ & $\begin{array}{r}-0.004(0.5) \\
0.43(0.4) \\
-0.88(1.9)\end{array}$ \\
\hline & \multicolumn{3}{|l|}{ Session 2} \\
\hline & $\begin{array}{l}\text { Group PLP } \\
(n=11)\end{array}$ & $\begin{array}{l}\text { Group PLS } \\
(n=9)\end{array}$ & $\begin{array}{l}\text { Group No } P L \\
(n=8)\end{array}$ \\
\hline $\begin{array}{l}\text { PST (log mg) } \\
\text { SC ( } \mu \text { mhos) } \\
\text { ST ( }{ }^{\circ} \text { Celsius) }\end{array}$ & $\begin{array}{r}0.30(0.6) \\
0.02(1.7) \\
-1.75(1.8)\end{array}$ & $\begin{array}{l}-0.21(0.6) \\
-0.06(1.5) \\
-1.25(1.5)\end{array}$ & $\begin{array}{r}0.11(0.7) \\
0.74(0.9) \\
-0.85(2.0)\end{array}$ \\
\hline
\end{tabular}




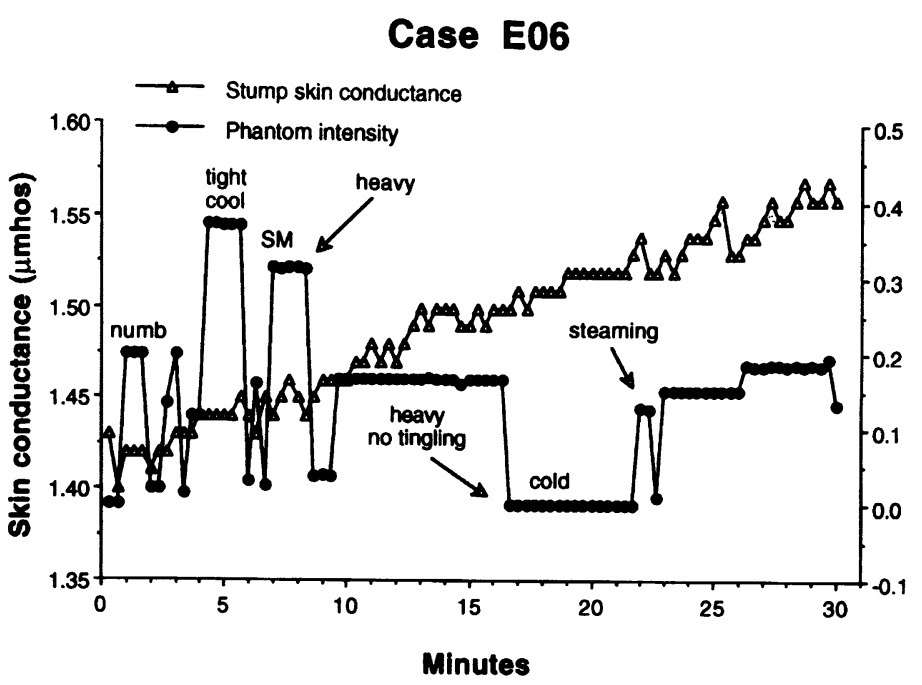

Case E07

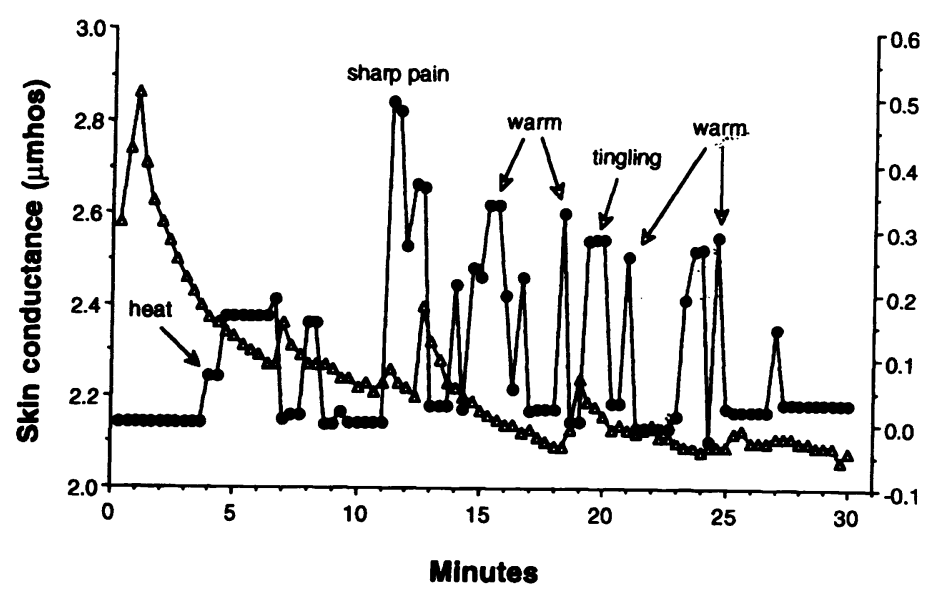

Figure 4 Plots of the relationship between stump skin conductance and various qualities of phantom limb pain for 2 subjects in Group PLP. There is no relationship between stump skin conductance and the intensity of phantom limb pain. Abbreviations as in fig 1.SM refers to somatosensory memory.

group PLS $(r(88)=0.29, \mathrm{p}<0.01)$ but not group PLP $(r \quad(88)=-0.02, \mathrm{p}>0.05)$. Together, these results indicate that phantom limb intensity and stump skin conductance are related in subjects reporting non-painful phantom limb sensations (that is, paresthesiae) but not in subjects with phantom limb pain (who report more varied qualities of sensation).

Table 4 Mean Pearson correlation coefficients ( $r$ ) for Groups PLP and PLS describing the linear relationship between phantom limb intensity (PLI) and stump skin conductance (SC), and PLI and stump skin temperature (ST). Group correlation coefficients were obtained by averaging the correlations for each subject and are based on a total of 90 points over 30 minutes. Also shown for each group is the number of significant $(p<0.002)$ correlations between PLI and stump SC, and PLI and stump ST for sessions 1 and 2 combined. P-values correspond to the Chi-squared test and ANOVA F-test for between-group comparisons of frequencies and means, respectively

\begin{tabular}{llll}
\hline & Group PLP $(n=11)$ & Group PLS $(n=9)$ & $p$-value \\
\hline $\begin{array}{l}\text { Correlation coefficient: }(r): \\
\text { PLI and stump SC }\end{array}$ & -0.02 & & $0.29 \star \star$ \\
PLI and stump ST & 0.06 & -0.17 & $\begin{array}{l}0.01 \\
n s^{\star}\end{array}$ \\
Number of significant rs: & & & \\
PLI and stump SC & $6 / 19(32 \%)$ & $8 / 12(67 \%)$ & 0.06 \\
PLI and stump ST & $8 / 19(42 \%)$ & $5 / 12(42 \%)$ & $\mathrm{ns}^{\star}$ \\
\hline
\end{tabular}

*not significant $(p>0.05)$

$\star \star$ significantly $(\mathrm{p}<0.05)$ different from zero.
It was not possible to determine the temporal primacy of phantom limb intensity and stump skin conductance which would have answered the question of whether changes in one preceded or followed changes in the other. The low sampling rate of one measurement per limb every 10 seconds was a limitation of the electromechanical relay which fixed the minimum possible time lag between consecutive measurements taken from the same limb at 20 seconds, clearly far too wide a time frame to capture the temporal relationship between the variables.

Detailed presentation of stump skin temperature was not undertaken since it was highly negatively correlated with skin conductance and thus provided little in the way of unique information. In addition, examination of plots of skin temperature and phantom limb intensity showed that skin temperature changed very slowly and lacked the sensitivity apparent in the measure of skin conductance.

Between-limb correlations The relationship between the psychophysiological variables measured at the stump and contralateral limb was evaluated for each subject by examining time plots of the two limbs on each session. In addition, the Pearson correlation coefficient describing the strength of the linear relationship between the two limbs was computed for each subject for skin conductance and skin temperature over both 30 minute sessions. The between-limb correlation coefficients were entered into separate 2-way ANOVAs (Group $\times$ Session) for skin conductance and skin temperature. All main effects and interaction terms for both analyses were not significant (all $p>0.05)$. For the majority of subjects there was a marked similarity in the pattern of activity measured at the stump and the contralateral limb suggesting that the processes responsible for moment-to-moment fluctuations in skin conductance and skin temperature are governed by a central mechanism and are not limb-specific.

\section{Discussion}

The relationship between phantom limbs and stump skin temperature

The significant limb temperature difference among phantom limb pain sufferers confirms Livingston's, ${ }^{9}$ and more recently Sherman et al's ${ }^{17}$ assertion that phantom limb pain is associated with reduced blood flow in the stump relative to the contralateral limb. However, the presence of a similar temperature difference in subjects with a painless phantom limb (defined primarly by paresthesiae) but not among amputees who report no phantom limb, raises the possibility that reduced stump temperature contributes to the paresthetic (dyesthetic) component of the phantom limb, both in groups PLS and PLP, but plays no role in generating other qualities of phantom limb sensation or pain.

In previous studies of amputees, ${ }^{17} 18$ reduced stump blood flow was confounded by the presence of both phantom limb pain and stump pain in most patients. With three excep- 


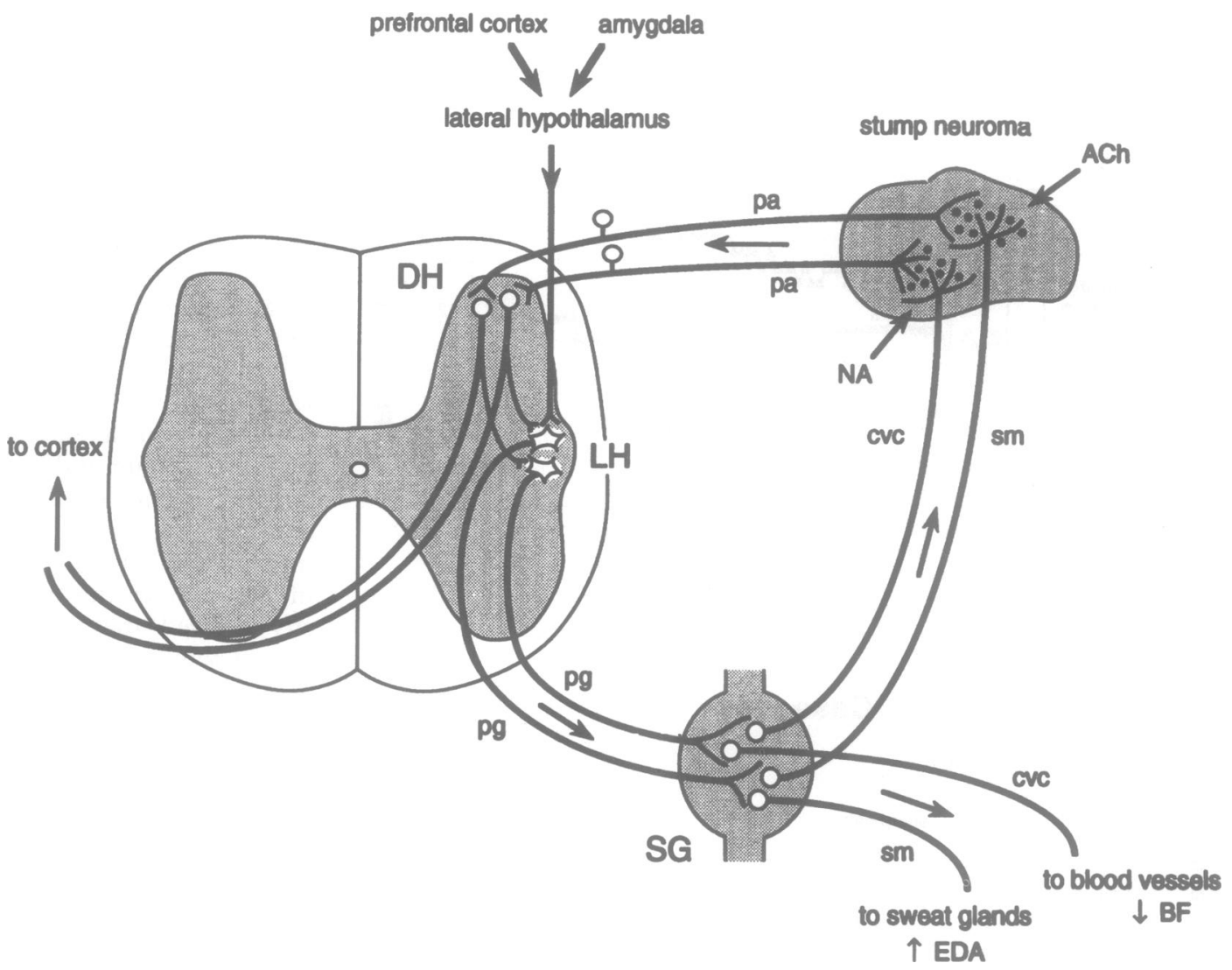

Figure 5 Schematic diagram illustrating a mechanism of symphathetically-generated phantom limb paresthesiae. Spontaneous activity or excitatory inputs descending from cortex (for example, due to the perception of a salient event, loud noise) increase the discharge rate of preganglionic ( $p g$ ) sympathetic neurons with cell bodies in the lateral horn $(L H)$ of the spinal cord and terminals in the sympathetic ganglion (SG). These neurons excite postganglionic noradrenergic (NA) cutaneous vasoconstrictor (cvc) and cholinergic ( $A C h$ ) sudomotor (sm) fibres which impinge on effector organs (vascular smooth muscle and sweat glands) in the stump and on sprouts from large diameter primary afferent ( $p a$ ) fibres which have been trapped in a neuroma. The release of ACh and NA on effectors organs results in increased electrodermal activity (EDA) and decreased blood flow (BF) to the stump. Release of these chemicals in the neuroma activates primary afferents which project to spinal cord dorsal horn (DH) cells subserving the amputated parts of the limb. These neurons, in turn, feed back to the preganglionic sympathetic neurons and project rostrally where the impulses contribute to the perception of phantom limb paresthesiae. If DH cells have been sensitised due to injury, or nociceptive primary afferents are activated, then the perception may be one of dysesthesiae. Adapted from Fields ${ }^{38}$ with permission.

tions, two of whom were in group No PL and therefore did not experience a phantom limb, all subjects in the present series were free of stump pain. Thus the finding that the lower stump skin temperature is characteristic of amputees who report a phantom limb, in the absence of associated stump pain, points to the importance of the vasomotor limb of the sympathetic outflow as a contributing factor to the perception of a phantom. Whether the temperature difference between the limbs reflects regional sympathetic hyperactivity or denervation sensitivity cannot be addressed by the present results since a large proportion of patients had peripheral vascular disease with or without diabetes mellitus. However, the three groups of amputees did not differ significantly with respect to the proportion of patients with peripheral vascular disease.

The relationship between phantom limbs and stump skin conductance

The absence of a between-limb difference in mean skin conductance levels for groups PLS and PLP may be related to the significantly lower skin temperature of the stump relative to the contralateral limb since neural activity in sudomotor and vasoconstrictor fibres are differentially affected by temperature. ${ }^{23}$ The lower stump temperature may have contributed to decreased electrodermal activity in the same way as a cool environment reduces activity in sudomotor fibres. Warming of the stump (to the temperature of the contralateral limb) may be expected to result in significantly higher levels of skin conductance at the stump relative to the contralateral limb. On the other hand, injury is known to produce effects that spread centrally to affect the contralateral limb. ${ }^{24}{ }^{25}$ Thus the absence of a between-limb difference in mean skin conductance levels may reflect amputation-induced changes in sympathetic function that extend to include the contralateral limb as well.

Although mean levels of stump skin conductance did not differ significantly from the contralateral limb in any group, changes in stump skin conductance over time correlated significantly with changes in the intensity of phantom limb paresthesiae among subjects in group PLS. Furthermore, the mean correlation coefficient between stump skin conductance and phantom limb intensity was significantly greater in group PLS than PLP, 
and was significantly greater than zero for group PLS but not group PLP. These results confirm and extend those of Katz et al ${ }^{19}$ who reported a significant relationship between stump skin conductance and phantom limb intensity in a single case study of an amputee with a non-painful phantom limb defined by paresthesiae. Two theories may explain the significant relationship.

Hypothesis 1: Sympathetic activity results in phantom limb paresthesiae The first hypothesis explains the relationship between sympathetic activity at the stump and the intensity of phantom limb sensations by assuming that neurotransmitter release from sympathetic fibres in the stump and stump neuromas activates large diameter primary afferents in close proximity. These afferent impulses give rise to referred paresthesiae upon reaching central cells subserving the amputated parts of the limb (fig 5).

There are several lines of evidence to support this hypothesis. First, sympathetic activity in the form of skin conductance responses and changes in skin temperature reflect the activity of post-ganglionic sudomotor and vasomotor fibres, respectively. ${ }^{23}$ Multiunit sympathetic activity recorded from skin nerve fascicles in awake humans shows a strong relationship to effector organ responses including vasoconstriction and sweat gland activity. ${ }^{23}$ These studies demonstrate that bursts of activity in sudomotor and vasomotor fibres are reliably followed by transient electrodermal responses and plethysmographic signs of vasoconstriction within the region of skin subserved by the sympathetic fibres under study.

Second, intraneural recordings from sensory nerve fascicles in conscious humans reveals a remarkably strong relationship between the perception of non-painful paresthesiae and spontaneous bursting activity in afferent fibres. $^{26}$ Finally, non-noxious percutaneous electrical stimulation of afferent nerves located in the stump of forearm amputees results in paresthesiae referred to a localised region of the phantom hand but not the stump. Subsequent alterations in the amplitude of electrical stimulation are paralleled by corresponding perceptual changes in the intensity of phantom limb paresthesiae which the subjects can track reliably using a manual device similar to that used in this study. ${ }^{27}$

Taken together, these studies raise the possibility, outlined in Figure 5, that changes in the intensity of phantom limb paresthesiae reflect the joint activity of cholinergic (sudomotor) and noradrenergic (vasomotor) postganglionic sympathetic fibres on primary afferents located in the stump and stump neuromas. Bursts of activity in sympathetic fibres produce transient vasoconstriction and heightened skin conductance levels. Shortly after, afferent fibres in stump neuromas would increase their rate of firing due to the liberation of acetylcholine and noradrenaline. Thus the moment to moment fluctuations in the intensity of phantom limb paresthesiae characteristic of the subjects' response patterns (figs 2 and 3), may partly represent a cycle of sym- pathetic-efferent and somatic-afferent activity. Increases in the intensity of phantom limb paresthesiae would follow bursts of sympathetic activity due to neurotransmitter release and decreases would correspond to periods of relative sympathetic inactivity.

Hypothesis 2: Phantom limb sensations result in sympathetic activity The second hypothesis explains the relationship between sympathetic activity at the stump and the intensity of phantom limb sensations by assuming that peripheral sympathetic activity, in the form of electrodermal and vasoconstrictive responses, occurs as a result of a perceived change in the intensity of the phantom limb. According to this hypothesis, the subject's detection of a change in phantom limb pain or other phantom limb sensations results in vasoconstriction and heightened electrodermal activity much as any anticipated and salient signal during a vigilance task produces a generalised orienting response. $^{28}$

For most subjects in this study, the two hypotheses cannot be distinguished on the basis of temporal primacy. In some patients (for example, Case E02 in fig 2) it is clear that heightened electrodermal activity preceded the perception of increasingly intense paresthesiae. For these patients, a sympathetic-efferent somatic-afferent cycle of activity may be responsible for triggering the perception of phantom limb paresthesiae.

In addition, the second hypothesis assumes that heightened electrodermal activity occurs as the result of a perceived change in the phantom limb and therefore predicts that the detection of any phantom sensation, whether painless or painful, would produce increases in electrodermal activity. The results indicate, however, that the patterns of stump skin conductance and phantom limb intensity were related significantly more frequently among subjects in group PLS (who reported phantom limb paresthesiae) than subjects in group PLP (who reported a host of different qualities of phantom limb pain) despite the fact that the painful phantom was more intense and hence more salient than the non-painful phantom (table 1). These findings are inconsistent with the second hypothesis which does not distinguish between the effects of different qualities of phantom limb sensation on stump skin conductance responses.

Given that stump skin conductance levels were not exaggerated and the two limbs showed a remarkably similar pattern of electrodermal responses over time, it is pertinent to ask why paresthesiae were experienced in the phantom limb but not the contralateral limb (or other parts of the body). Evidence suggests that the threshold for impulse generation is lower both in regenerating primary afferents in the stump and in deafferented central cells subserving the phantom limb than it is in the intact nervous system. Regenerating sprouts which have formed a neuroma are exceedingly sensitive to the post-ganglionic sympathetic neurotransmitters noradrenaline ${ }^{29}$ and acetylcholine $^{30}$ and discharge rapidly when these substances are present. In contrast, intact 
peripheral fibres do not show this chemosensitivity, and thus have a higher threshold compared with regenerating sprouts. Second, deafferentation results in a loss of inhibitory control over cells in the dorsal horn and more rostral sensory structures ${ }^{3132}$ giving rise to the perception of a phantom limb. ${ }^{32}$ This implies that the threshold for detecting sympathetically-triggered afferent impulses arising from stump neuromas should be lower than at other, intact body sites since stump impulses would be subject to less inhibition upon reaching the spinal cord. This fits well with the observation that the threshold for detecting sensations in the phantom limb during stimulation of the stump is lower than at the site of stimulation itself. $^{33}$ Together, these two observations may explain the propensity for the phantom limb to be the site of sympathetically-generated referred sensations even in the absence of regional sympathetic hyperactivity.

Pressure sensitivity thresholds of-amputation stumps The lack of a significant difference between pressure sensitivity thresholds at the stump and contralateral limb is surprising since amputation stumps have consistently been found to display greater skin sensitivity than the corresponding region of the contralateral limb. Lowered thresholds at the stump have been demonstrated in adults for light touch, two-point discrimination and point localisation after amputations of the upper extremity ${ }^{34}$ and for two-point discrimination following lower extremity amputations. ${ }^{35}$ Similar results have been found for pressure sensitivity and two-point discrimination thresholds in children with congenital absence of limbs. ${ }^{3637}$ Most of these studies included patients with amputations due to trauma or accident and measured tactile acuity from several points on each limb. It is possible that the lack of a significant between-limb difference in sensitivity thresholds in the present study stems from the inclusion of amputees with peripheral vascular disease and diabetes mellitus as well as the restricted sampling of a single region on each limb.

Recent evidence supports the view that phantom limb pain is not a unitary syndrome but a symptom class with each class subserved by different aetiological mechanisms. Consistent with this view, the present study proposes that one mechanism underlying the perception of phantom limb paresthesiae or dysesthesiae involves a sympathetic-efferent somatic-afferent cycle in which both postganglionic sudomotor and vasomotor fibres participate. Fluctuations in the intensity of paresthesiae referred to the phantom limb reflect corresponding changes in peripheral sympathetic nervous system activity which may occur spontaneously or be induced by emotionallycharged events. Other qualities of phantom limb sensation or pain (for example, cramping, shooting, somatosensory memory pains) which do not correlate with sympathetic nervous system activity at the stump may be triggered by activity in other peripheral structures (for example, muscle) or more central neural structures. Simultaneous microelec- trode recordings of post-ganglionic sympathetic and primary afferent fibres in amputation stump neuromas would provide valuable information about the qualities of referred phantom sensation that are associated with sympathetically-generated afferent activity.

I thank the staff and patients of the following hospitals and institutions for their kind and helpful cooperation: Catherine Booth Hospital Centre, Fédération des Personnes Amputée du Québec, J E Hanger Inc, Montreal Convalescent Hospital Centre, Montreal General Hospital, Orthomedics Inc, Royal Victoria Victoria Hospital, St Anne's Veterans Hospital. I am grateful to Professor Ronald Melzack for his generous support of this
project and helpful comments when preparing the manuproject

prejet.

This study was carried out when the author was a doctoral student at McGill University. The research was supported by Grant A7891 from the National Sciences and Engineering Research Council of Canada to Professor Ronald Melzack, and by postgraduate scholarships from the Medical Research Council of Canada, and the Fonds FCAC pour l'Aide et le Soutien à la Recherche (Quebec Government) to the author. Preparation of the manuscript was supported by fellowships
from the Health Research Personnel Development Program of the Ontario Ministry of Health and the Medical Research Council of Canada. The results and conclusions derived herein are those of the author, and no official endorsement by the Ontario Ministry of Health is intended or should be inferred.

1 Jensen TS, Rasmussen P. Phantom pain and related phenomena after amputation. In: Wall PD, Melzack R, eds. Textbook

2 Sherman RA, Sherman CJ, Parker L. Chronic phantom and stump pain among American veterans: results of a study. Pain 1984;18:83-95.

3 Sherman RA. Stump and phantom limb pain. Neurologic Clinics 1989;7:249-64.

4 Sherman RA, Arena JG, Sherman CJ, Ernst JL. The mystery of phantom pain: Growing evidence for psychophysiological mechanisms. Biofeedback and Self-Regulation 1989;14:267-80.

5 Katz J, Melzack R. Pain "memories" in phantom limbs: Review and clinical observations. Pain 1990;43:319-36.

6 Jänig W. Causalgia and reflex sympathetic dystrophy: In which way is the sympathetic nervous system involved? which way is the sympathetic

7 Devor $M$. Nerve pathophysiology and mechanisms of pain in causalgia. If Autonomic Nervous System 1983;7: 371-84.

8 Roberts WJ. A hypothesis on the physiological basis for causalgia and related pains. Pain 1986;24:297-311.

9 Livingston WK. Fantom limb pain. A report of ten cases in which it was treated by injections of procaine hydrochloride near the thoracic sympathetic ganglions. Arch Surg 1938;37:353-70.

10 Kallio KE. Permanency of results obtained by sympathetic surgery in the treatment of phantom pain. Act Orthopaed Scand 1950;19:391-7.

11 Marsland AR, Weekes JWN, Atkinson R, Leong MG. Phantom limb pain: a case for beta blockers? Pain 1982;12:295-7.

12 Noordenbos W. Pain. Amsterdam: Elsevier, 1959:160.

13 Echlin F. Pain responses on stimulation of the lumbar sympathetic chain under local anesthesia. $\mathcal{f}$ Neurosurg 949;6:530-3

14 Sliosberg A. Les Algies des Amputés. Paris: Masson, 1948: 80-1.

15 Kristen H, Lukeschitsch G, Plattner F, Sigmund R, Resch $P$. Thermography as a means for quantitative assessment of stump and phantom pains. Prosthetics and Orthotics International 1984;8:76-81.

16 Nyström B, Hagbarth KE. Microelectrode recordings from transected nerves in amputees with phantom limb pain. Neurosci Lett 1981;27:211-6.

17 Sherman RA. Direct evidence of a link between burning phantom pain and stump blood circulation: a case report. phantom pain and stump blood

18 Sherman RA, Bruno GM. Concurrent variation of burning phantom limb and stump pain with near surface blood in phantom limb and stump pain with near surf

$19 \mathrm{Katz} J$, France C, Melzack R. An association between phantom limb sensations and stump skin conductance during transcutaneous electrical nerve stimulation (TENS) applied to the contralateral leg: A case study. Pain 1989;36:367-77.

$20 \mathrm{Katz}$ J, Melzack R. Auricular TENS reduces phantom limb pain. F Pain and Symptom Management 1991;6:73-83.

21 Fowles DC, Christie MJ, Edelberg R, Griggs WW, Lykken DT, Venables PH. Publication recommendations for electrodermal measurements. Psychophysiol 1981;18: 232-9.

22 Melzack R. The McGill Pain Questionnaire: major properties and scoring methods. Pain 1975;1:277-99.

23 Bini G, Hagbarth KE, Hynninen P, Wallin BG. Thermoregulatory and rhythm-generating mechanisms governing the sudomotor and vasoconstrictor outflow in human cutaneous nerves. I Physiol (London) 1980; 
306:537-52

24 Woolf CJ. Long term alterations in the excitability of the flexion reflex produced by peripheral tissue injury in the chronic decerebrate rat. Pain 1984;18:325-43.

25 Coderre TJ, Melzack R. Cutaneous hyperalgesia: contributions of the peripheral and central nervous systems to the increase in pain sensitivity after injury. Brain Res 1987; 404:95-106.

26 Ochoa JL, Torebjörk HE. Paraesthesiae from ectopic impulse generation in human sensory nerves. Brain impulse generation

27 Anani A, Körner L. Discrimination of phantom hand sensations elicited by afferent electrical nerve stimulation in below-elbow amputees. Med Progr Technol 1979;6: in below-

28 Voronon LG, Bonfitto M, Vasileva VM. The interrelation of the orienting and conditioned reflex to time in man. In Sokolov EN, Vinogravoda DS, eds. Neuronal mechanisms of the orienting reflex. New Jersey: Lawrence Erlbaum, 1975:252-63.

29 Wall PD, Gutnick M. Properties of afferent nerve impulses originating from a neuroma. Nature 1974;248:740-3.

30 Diamond J. The effect of injecting acetylcholine into normal and regenerating nerves. F Physiol (London) 1959;145: 611-29.

31 Melzack $\mathbf{R}$, Loeser JD. Phantom body pain in paraplegics: Evidence for a central "pattern generating mechanism" for pain. Pain 1978;4:195-210.

32 Wall PD. On the origin of pain associated with amputation. In: Siegfried J, Zimmermann M, eds. Phantom and stum pain. New York: Springer-Verlag, 1981:2-14.

33 Carlen PL Wall PD, Nadvorn $H$, Steinbach T Phantom limbs and related phenomena in recent traumatic amputations. Neurol 1978;28:211-87.

34 Haber WB. Effects of loss of limb on sensory functions. $f$ Psychol 1955;40:115-23.

35 Teuber HL, Krieger HP, Bender M. Reorganization of sensory function in amputation stumps: two-point discrimination. Federal Proc 1949;8:156.

36 Wilson J, Wilson BC, Swinyard CA. Two-point discrimination in congenital amputees. $\mathcal{f}$ Compar Physiolog Psychol 1962;55:482-5.

37 Weinstein S, Sersen EA, Vetter RJ. Phantoms and somatic sensation in cases of congenital aplasia. Cortex 1964;1: 276-90.

38 Fields HL. Pain. New York: McGraw-Hill, 1987:153. 